\title{
On theory, technique and text: guidelines and suggestions on publishing international human resource management research
}

Article

Accepted Version

Raghuram, S., Brewster, C., Chen, X.-P., Farndale, E., Gully, S. and Morley, M. J. (2017) On theory, technique and text: guidelines and suggestions on publishing international human resource management research. The International Journal of Human Resource Management, 28 (12). pp. 1640-1660. ISSN 1466-4399 doi:

https://doi.org/10.1080/09585192.2017.1307244 Available at https://centaur.reading.ac.uk/70172/

It is advisable to refer to the publisher's version if you intend to cite from the work. See Guidance on citing.

To link to this article DOI: http://dx.doi.org/10.1080/09585192.2017.1307244

Publisher: Routledge

All outputs in CentAUR are protected by Intellectual Property Rights law, including copyright law. Copyright and IPR is retained by the creators or other copyright holders. Terms and conditions for use of this material are defined in the End User Agreement. 


\section{www.reading.ac.uk/centaur}

\section{CentAUR}

Central Archive at the University of Reading

Reading's research outputs online 
On Theory, Technique and Text: Guidelines and Suggestions on Publishing International Human Resource Management Research

\author{
Sumita Raghuram (sur19@psu.edu), The Pennsylvania State University, USA \\ Chris Brewster, Reading University, UK \\ Xiao-Ping Chen, University of Washington, USA \\ Elaine Farndale, The Pennsylvania State University, USA / Tilburg University, The Netherlands \\ Stan Gully, The Pennsylvania State University, USA \\ Michael J Morley, University of Limerick, Ireland
}




\title{
On Theory, Technique and Text: Guidelines and Suggestions on Publishing International Human Resource Management Research
}

\begin{abstract}
Publishing international human resource management (IHRM) research continues to be a challenge for seasoned as much as junior faculty. Quantitative and qualitative studies exploring HRM-related topics involving multiple countries or complex contextual factors raise issues of developing an appropriate research question, presenting multilevel methodologies, and making a contribution in which context stands central. In this Editorial, we reflect on such issues as discussed at the $2^{\text {nd }}$ Global Conference on International Human Resource Management held at the Pennsylvania State University (USA) in 2015. Journal editors, reviewers and authors contribute to provide practical suggestions on the craft of getting published, including design of a study, developing a writing style, and dealing with journal feedback. Finally, we explore some myths and misperceptions around publishing IHRM research in high-ranking journals.
\end{abstract}

KEYWORDS: International human resource management; Theoretical contribution: Measurement; Quantitative; Qualitative. 


\section{Introduction}

Over the past few decades, IHRM has gained prominence as an area of study (Tung, 2016). This is in part due to the worldwide growth of multinational enterprises (MNEs). It has been estimated that there are more than 100,000 parent transnational corporations and nearly 900,000 foreign affiliates (UNCTAD, 2011). Scholars and practitioners alike grapple with issues confronting a global workforce and their employers. Globalization and competitive forces on an international platform have forced MNE and local firms alike to reevaluate their talent strategies. Research has attracted commensurate interest as both scholars and practitioners strive to understand HRM in this global landscape. In fact, a quick search on the Web of Science database from 1985 to 2015 for terms such as 'international' or 'global' or 'world' or 'multinational' or 'transnational' combined with "human resource management' or 'human capital' or 'talent' or 'expatriate" in management related outlets shows an exponentially rising number of published articles and citation rates, especially over the last decade (see Figures 1 and 2, respectively). These numbers reflect the excitement surrounding this area of study, as we strive to draw attention to our research and to disseminate knowledge in journals that enjoy wide readership.

>>Insert Figures 1 and 2 about here $<<<$

The second Global Conference on International Human Resource Management (IHRM) in 2015 at the Pennsylvania State University attracted numerous submissions, some of which subsequently withstood the review process to be included as part of this Special Issue. However, there were many manuscripts that did not make it to the final round of either the conference program or the Special Issue. This experience, coupled with our deliberations at a publishing workshop run at the conference itself, motivated us to write this editorial on what constitutes 
publishable 'international' HRM research, and share advice on how we, as a group of scholars, can write impactful articles in IHRM.

Our conference workshop on Publishing IHRM Research served as a platform to share experiences, insights and advice about how we can more effectively create and publish high quality manuscripts. The workshop speakers included journal editors, reviewers and authors. In this editorial, we bring together some of their perspectives with the objective of presenting a number of recommendations or 'good practices' that may help in guiding future researchers. We recognize that some of the suggestions here may be generic, however, we attempt to focus specifically on IHRM content.

IHRM as a field includes studies of human resource management (HRM) that are in some way related to an international context (see also Farndale et al., 2017 in this volume). The field includes studies of HRM specifically within MNEs, including expatriate management and global mobility, whereby the international context is by definition incorporated in the nature of the firm. There are also studies of Comparative HRM that focus on making a connection between one or more national contexts and associated HRM activities. This can include the application of institutional and/ or cultural theories that explain why a given HRM practice is likely to be present and more/ less effective in a given country setting.

In this IHRM publishing editorial, we describe how best to conceptualize and set up a study keeping in mind the theoretical contributions and consequent study design, including data appropriate to theory and data analyses. We explore what it means to write an 'internationally' focused manuscript, explaining why we need to go beyond the notion of seeing 'international' as simply referring to any dataset collected outside the U.S.A., and instead emphasizing the context and its centrality to generating meaning. We provide suggestions for writing in a style that 
matches the journal requirements, as well as following logical steps for hypotheses development (if these are a part of the manuscript). Finally, we provide suggestions and guidelines for authors to prepare a revision that is timely, comprehensive and responsive to feedback.

\section{Theoretical Contribution}

How do I wish to contribute to my field or as Huff (1999) put it, which conversation going on in my field do I wish to join? This may be a philosophical question, but in many ways an answer to it fundamentally determines the direction of the study that the researcher embarks upon. Clear thinking at this initial stage serves as the foundation for the study design, data analyses and how these are highlighted in manuscript submissions. As with any field, the primary goal of IHRM research is to advance theory and understanding of the phenomena under investigation. Strong theory explains the relationship between the constructs in the phenomena we observe and on which we collect data, and is relevant and interesting (Byron \& Thatcher, 2016). Theory articulates what factors are involved, how they are related and the boundary conditions of the theory (who, where, and when; Whetten, 1989). It explains the logic, process or conditions under which constructs of interest are related - thereby providing sound reasons for expecting such relationships (e.g. Sutton \& Staw, 1995; Weick 1995). Several articles provide guidance for what falls under building new theory and testing existing theory (e.g. Colquitt and Zapata-Phelan, 2007), and it is important to reflect upon this specifically from the perspective of research in IHRM.

Borrowing from the typology developed by Colquitt and Zapata-Phelan (2007), we provide examples here of IHRM articles illustrating the types and range of theoretical contribution. According to them, building new theory can range from exercises aimed at replicating previously demonstrated effects (minimal contribution) to introducing a new 
construct (rich contribution). Testing existing theory can range from inductive analysis with some logical speculation to developing grounds for predicting existing theory. We discuss here these five types of contributors to theory: reporters, testers, qualifiers, builders, and expanders. Reporters categorize or classify phenomenon that they measure or observe. In IHRM research these classifications can be based on differences in HRM practices between countries or cultures. With the help of such classification, readers are made aware of variations in practice. It forms an essential first step towards identifying the causes behind such variations. IHRM researchers have attempted to explain these differences based on cultural, institutional, economic or other factors that are associated with the country(ies) using pre-existing frameworks (e.g. for culture, Hofstede, 1908). Examples of studies illustrating the heterogeneity of context in HRM research, include comparison of Chinese and US HRM practices (Von Glinow and Teagarden, 1988); cross-country differences in staffing practices (Ryan, McFarland \& Baron, 1999); compensation practices (Schuler \& Rogovsky, 1998) and configurations of corporate HRM roles in MNEs (Farndale, 2010). (For an extensive overview of the comparative HRM literature, see: Brewster \& Mayrhofer, 2012). Further, some of this research attempts to find convergence or divergence in the practices across the countries and provide post-hoc reasons behind these observations (e.g. Goergen, Brewster, Wood \& Wilkinson, 2012; Mayrhofer, Brewster, Morley \& Ledolter, 2011).

Testers focus on testing existing models rather than on building new theory. In this regard, it is important to note that several manuscripts claim to be international because they collect data that are international even as the relationships being tested exist in the literature. For example, Tanova and Holtom (2008) test job embeddedness factors to explain voluntary employee turnover in four European countries and find support for the model in different work 
contexts. Björkman, and Xiucheng (2002) examine the impact of HRM practices on the performance of Western firms in China. Many of these articles examine relationships in countries that were not represented in the existing literature. This research is valuable in demonstrating similarities to, or differences from known relationships. It adds to generalizability but may not advance the IHRM theory significantly (see also: Ahlstrom, 2010).

Qualifiers represent moderate levels of theory testing and building (e.g., use of new moderators or mediators). Some studies in IHRM research propose meaningful moderators (specific to a given country context) that would enhance or weaken a relationship posited in an existing theory. Doing this demonstrates, for example, the importance of culture (beliefs, values, norms, communication styles) in altering the relationship between HRM practices and employee work behaviours and performance, which advances the existing theory by providing boundary conditions. It is important for IHRM researchers to explore underlying mechanisms that offer different explanations for the same relationship observed elsewhere. For example, personorganization fit has been found to have positive relationships with job satisfaction and job performance in both Western and Eastern countries (e.g., Kristof-Brown, Zimmerman, \& Johnson, 2005; Li, 2006), however, the meaning of fit and the process through which fit occurs might differ significantly in the two different cultural contexts. Chuang, Hsu, Wang, Judge (2015) found that compared to U.S. workers, the Taiwanese employees have broader views regarding person-organization fit, and view fit as having a dynamic rather than static nature. They then make constant adjustments and changes to their own actions to reach the state of fit, and achieve satisfactory work outcomes. Likewise, Raghuram (2011) found that a paternalistic supervisory style enhances the effects of job challenge on organizational identification among Indian software professionals. Thus, uncovering the specific mechanisms that attune to a 
particular culture provides an answer to the 'why' or 'how' question related to a phenomenon, which enriches the existing theory.

Builders represent the emic approach (Morris, et al, 1999), which in IHRM involves building new theories based on a country context that has its unique political, economic, legal, and socio-cultural characteristics. To do this, inductive methods are often appropriate, including archival searches, interviews, and case studies. One successful example to emulate is Zhang, Waldman, Han, and Li (2015) who identified a novel leadership phenomenon in China which they labelled as paradoxical leader behaviours, defined as the seemingly conflicting yet interrelated behaviors used to meet competing workplace demands simultaneously and over time. They then empirically demonstrated five behaviors that meet this definition, developed a scale measuring them, and explained why the paradoxical behaviors are common among leaders in Chinese organizations. Through these efforts, they established a new theory of leadership that explained differences in leader behaviors across international contexts.

Expanders develop new constructs and new formulations of existing theories. Their thinking is often inductive and their objective is to take existing literature in a new direction. There is some exemplary research in this area in IHRM as well. For instance, the cultural framework developed by Hofstede (1980) was initially based on several in-depth interviews and observations and followed up with surveys. He introduced the four cultural dimensions (later expanded to five and then more) to the international research which sowed the seeds for the exploration of new relationships in organizations. Similar construct development includes the identification of paternalism and context-dependent communication (Adair, Buchan, Chen, \& Liu, 2016). 
Unfortunately, however, the development of new constructs has been slow. Significant opportunities exist for advancing the field of IHRM by adopting a cross-disciplinary approach. Examples might include merging migration studies or behavioral economics with expatriate management literature to examine what motivates or makes expatriation successful, or merging post-colonial power perspectives with MNE adoption of HRM practices. Similarly, it seems important to look beyond culture as the key factor differentiating IHRM contexts and build more theory involving other aspects of the transnational context such as history, political systems, country size or wealth, class structures, and other institutional factors (e.g. Vaiman \& Brewster, 2015). Once an appropriate theoretical contribution has been established, attention then turns to the importance of the empirical study.

In summary, for IHRM, there are two primary approaches for international research to make a theoretical contribution to the existing literature. One is 'theories in context' (Whetten, 2009) or the etic approach (Morris, Leung, Ames, \& Lickel, 1999), which often involves testing existing theories in a different cultural context by discovering moderating variables or boundary conditions that would refine or extend the existing theories (i.e. testers or qualifiers). The other is 'theories of context' (Whetten, 2009), using context itself as a source for novel theorizing (i.e. builders). In general, we observe more studies published adopting the first approach, and very few publications that adopt the second approach, even though 'theories of context' are much more valuable in broadening and deepening our understanding of international phenomena.

\section{Data and analyses}

Many manuscripts purport to examine HRM systems, processes, theories, and outcomes in an international context. However, there tends to be slippage between what the authors describe as the purpose of their manuscript and what actually takes place in the data collection and analysis 
portion of the manuscript. This is true for both qualitative and quantitative research. Qualitative research generally refers to the exploration of phenomena by developing an understanding of underlying meanings and identifying patterns of relationships within highly contextualized settings. Qualitative research typically focuses on descriptive approaches such as case studies, observation, interviews, and thematic analyses. Quantitative research, in contrast, focuses more on numerical data collection, statistical analysis, and mathematical modelling of a phenomenon

of interest, with a particular focus on hypothesis testing using measured variables and analyses of relationships among variables (Gephart, 2004).

Strong qualitative manuscripts apply a level of rigor equal to, or even beyond, that applied to quantitative ones. Likewise, a high quality quantitative manuscript often has roots in an initial qualitative effort to: (1) better understand the phenomena being investigated; (2) integrate specific country, organizational, or unit level factors into the quantitative data collection effort; and (3) develop appropriate measures and controls to increase the internal and external validity of the study.

Despite their differences in approach to scientific study, both approaches have overlapping concerns when it comes to thinking about publishing manuscripts on HRM in an international context. Here we identify some commonly seen errors and provide some suggestions to correct them.

\section{Level of measurement}

A useful framework to use when thinking about IHRM research is levels of analysis (Klein, Dansereau, \& Hall, 1994). At a minimum, IHRM researchers often must consider country level factors, organizational level factors, and individual level factors. For quantitative research in particular this impacts sampling, measurements, wording of questions, analyses used, and 
conclusions. Cross-level effects are more complex (e.g., national culture affecting individual attitudes) and require careful attention. The intended purpose of the manuscript must connect to the sampling, measurement, and analysis approaches used.

For example, researchers sometimes assume that national culture is an individual level attribute and accordingly proceed to measuring individual values such as collectivism/ individualism. However, national cultures are a collective attribute of a group of people which cannot be directly mapped onto individuals (e.g. Hofstede, 2004; 1991). Interviewing or surveying an individual (or individuals) and asking them about the culture confounds individual differences with true country level differences. This is not to say that individuals cannot have values that reflect certain aspects of cultural dimensions. The key issue is that a single individual cannot be made representative of broader cultural factors. Almost by definition, if national culture exists at higher levels than the individual level, then it must manifest as shared values across individuals within a context (Klein \& Kozlowski, 2000).

It is important that the measure must map onto the phenomenon of interest. If the interest is at the country or cultural level then the measures themselves must be at the country or cultural level. Individual perceptions and attitudes may be gathered but if the intent is to aggregate to the unit or country level then agreement or 'sharedness' must be established to allow for such aggregation (LeBreton \& Senter, 2008). Additionally, country or unit level effects must be demonstrated or the effect cannot be examined at these levels. Lack of variability at a higher level impedes analysis and theorizing at that level. If interviewing or collecting observations, then multiple individuals must be included for each culture, country, or unit that is being examined to enable separation of the individual from the higher level effect.

\section{Sampling}


If the researcher is interested in higher level effects then multiple people or observations from the higher level are necessary. For example, it is not possible to have only a few people from a given country to be representative of the entire country's effects. Sometimes we see articles in which a single person or a small group of people from a given organization is supposed to represent the country or culture level effects. The problem is that the individual or small group cannot be disentangled from the business unit, organization, or country/culture levels. Sampling is necessary across people and business units within a country (or culture) to extrapolate to the higher level. In institutional research, similar concerns apply to studies that use just a few organizations to represent whole economies.

Another important consideration is the choice of countries to include in the sample. Sampling across two countries which are fairly similar in their theorized contexts is unlikely to yield much variance in the constructs of interest (e.g. national cultures of Canada and U.S.A.). Indeed, many leading international business journals often may not consider a two-country study as being 'international' unless there is a compelling reason to examine the two specific countries under consideration. The analysis and subsequent results may not yield results that are either significant or interesting. To create variance, country choice has to go hand in hand with theorizing and sampling for the main constructs that are of interest.

Central to our argument here is the importance of giving serious consideration to including researchers from the contexts and cultures being studied from the very outset of the program of research. The experience from the longstanding CRANET research network on comparative HRM demonstrates that there are few substitutes for this 'local' knowledge in formulating the research question in the first instance, establishing its centrality in the location under study, signalling the contextual legitimacy of the study to potential respondents and 
making sensible decisions about how data-gathering might best proceed in that specific environment (Parry, Stavrou-Costea, \& Morley, 2011).

Many top journals have a list of what they refer to as 'fatal errors'. It is in researchers' interest to be aware of these and not get carried away with any opportunity they see to collect data (and later not know what to do with it). First, for survey studies, collecting cross-sectional data from the same source (e.g., subordinates only) is susceptible to the common method error (Podsakoff, McKenzie, Podsakoff, \& Lee, 2003). So a desirable survey design will collect timelagged or longitudinal data from different sources (especially for independent and dependent variables) if causal inference or mediation effects are implied in the theoretical model. If the researcher is interested in adopting a 'reporter' stance in theorizing then cross-sectional data may work because data is to be simply categorized as per country/ culture differences.

\section{Analyses}

Much like data collection/ study design, the data analyses must match the level of theorizing. If the intent is to examine cross-level effects such as how organizations function differently across countries and the data is at the individual or even organizational level, then using standard multiple regression will almost never work because of violations of assumptions of independence. In this example, we have non-independence of observations because there are multiple observations from the same level (e.g., multiple organizations within each country or multiple individuals within organizations within each country). So it is necessary to carry out multilevel modelling to first take into account the country based differences before moving on to exploring cross-organization differences. If the hypotheses are about individuals within countries then cross level modelling may be necessary. Techniques for this type of analysis include hierarchical linear modelling (Hofmann, 1997; Hofmann, Griffin, \& Gavin, 2000), random 
coefficient modelling (Kirkman, Chen, Farh, Chen, \& Lowe, 2009), or multiple-level modelling (Peterson, Arregle, \& Martin, 2012).

Qualitative analysis on the other hand, by its very nature provides a rich opportunity to capture the contextual differences. It helps to explain how context impacts the phenomena of interest at different level of analyses (including temporal, spatial, and hierarchical), and especially when it is difficult to distinguish the different levels.

When analysing the data, it is important to note that there are many different kinds of qualitative analyses, such as simple content analyses (Hsieh \& Shannon, 2005), grounded theorizing (Glaser \& Straus, 2009; Strauss \& Corbin, 1990) and the more complex process theorizing (Langley, 1999). Researchers have to be very clear as to which method they are using. The method has to be appropriate in answering their research question, and accordingly utilizing suitable data. Frequently researchers claim that they are using 'grounded theorizing' in their methodology whereas it appears that they are simply categorizing their qualitative data using content analyses to answer certain hypothesized research questions (e.g. cross country differences in selection practices). This is a deductive approach and substantiates static variances. Grounded theorizing on the other hand is an inductive process whereby the researcher analyses the data, searches for common themes, and then integrates all the themes in a theoretically coherent framework. In the process the researcher constantly switches back and forth between the data and the developing theory - to keep it grounded (Glaser \& Straus, 2009). Process theorizing, also inductive, is temporally embedded, accommodating all levels of analyses simultaneously, addressing questions related to change or evolution (Langley, 1999). As an example, this approach may be used by IHRM researchers wanting to study changes in HRM practices as MNEs expand (or contract), and developing a theory based on this process. What is 
important in this particular research endeavour is the collection of data at different points in time which help in explaining changes as they occur in different units in different countries within each MNE of interest. This would match the level of qualitative observations to the level of theory.

In carrying out quantitative analyses it is very important to show that the variables have acceptable properties before testing the model. This may require conducting confirmative factor analysis (CFA) at the appropriate level of analysis to demonstrate the convergent and divergent validity of the constructs in the theoretical model. It may require demonstrating adequate reliabilities. Likewise for some types of qualitative data analyses it may be necessary to demonstrate inter-rater agreement at acceptable levels (Landis \& Koch, 1977).

It is important to collect data in a language that is well understood by the respondents. This may require translation of items developed in one language and used in another. This process should be carried out carefully, ensuring that there is conceptual, functional and metric equivalence and construct clarity (Cascio, 2012). Specific to IHRM research, the same construct may contain different content or manifest in different ways in different cultures, and the nominal value on a Likert scale (e.g., 3 on a 5-point scale) may indicate a different degree of agreement for a participant in different cultural contexts. A useful guide for such an exercise is provided in Van de Vijver \& Leung's (1997) book on methods and data analysis for cross-cultural research.

\section{Writing the Manuscript}

It is difficult to overstate the importance of writing clearly and in an impactful way. It is hard work to write well and it requires several iterations to create a quality final product. It helps to get feedback from friends and colleagues to improve the manuscript before sending it out for review. Commonly identified issues with writing have included 'foggy presentation' (e.g., 
obscurity in meaning or explanation; overuse of jargon), 'expecting readers to read the author's mind' (e.g., lack of definition of terms; little explanation of theory), and 'failure to tell a story' (e.g., no clear, direct and compelling story that hooks the reader in the beginning and follows through to the end) (Ragins, 2012). Being able to tell a good story is important for publishing qualitative or quantitative research. We found similar issues in manuscripts we have reviewed and to this list we would add: 'setting the stage' (explaining early on why the topic is important) and 'highlighting the international aspect of the IHRM research' (identifying what makes this international -- it's not enough to say this "hasn't been studied in this particular country").

\section{Stating the research question}

The initial research question that the researcher is seeking to answer can be considered the trajectory for, and the quintessence of, the entire research programme, the manner in which it is likely to unfold and the eventual place and space created for the researcher in the discipline as it evolves over time. This question serves as the generative mechanism for the subsequent decisions regarding the conceptualization of the IHRM phenomenon of interest, the design of the fieldwork, the subsequent data handling and its eventual reporting. Given its significance, the research question is best presented within the first few paragraphs of the manuscript and should clearly signal how answering it will augment the body of knowledge about the phenomenon of interest. In this way it serves to communicate in a clear and unambiguous way the added value of the entire research effort.

\section{Development of the hypotheses and propositions}

Careful development of the argument that would naturally lead the reader to the stated hypotheses (or propositions) is essential. Firstly, the connection between the hypotheses/ propositions and the core research question being addressed should be obvious (yet interesting) 
to the reader, calling attention once again to the centrality of that question to the subsequent steps on the research journey and their meaningfulness or otherwise. The development of the hypotheses and propositions should have a logical and ample reasoning embedded in prior literature and lead to the relationships under consideration. Critical in all of this is the making of sensible decisions about the focus of the central hypotheses (or propositions) and how these may be defended as critical parts of the research puzzle that are currently worth pursuing, relative to a potentially broader suite of issues that could form part of the picture. Once again, this is especially important in the IHRM field where, as highlighted above, the territory covered is often diverse, and contextual explanations of the data may exhibit elements of commonality or difference in the locations under study. Above all, in the case of hypotheses, measures are important (Whetten, 1989:49) and as highlighted earlier, several aspects of the measurement challenge are acute in IHRM.

\section{Methodology description}

It is very important to describe how data were collected in any study. The timing, sourcing, sampling, and researchers involved should be made understandable to the reader. This is especially important in the case of qualitative manuscripts. A clear account of measurement and/ or measurement equivalence is essential, along with a clear statement on how it can be defended against the backdrop of the complexities that arise in conducting IHRM research.

\section{Writing Style}

Developing an effective writing style is an important part of the armoury of any researcher and time spent on developing and perfecting an authentic writing style is an important part of learning one's craft. To get readers 'hooked on' to the manuscript it is essential that authors expend considerable time and energy in writing and rewriting their thoughts. It will require 
multiple drafts and the willingness to abandon what authors may have spent many hours writing. Johanson (2007) advocates that authors should sit in the reader's chair in developing their arguments, positioning their contribution and enhancing their prospect of publication. She notes that:

“many writers don't think often enough about how their readers will make sense of what they've written. Reading is always an exercise in sensemaking. Guiding your readers' sensemaking is the secret to successfully navigating the publication process”. (Johanson, 2007: 291)

This process of focusing on the likely sensemaking of the reader can assist in argument refinement and the accessibility of the core ideas advanced in the manuscript, all of which are critical to securing a favourable decision in the review process. A practical conduit to enhancing such sensemaking, and one increasingly prescribed by highly ranked journals, is the securing of developmental feedback from colleagues and peers as part of the manuscript development and idea refinement process in advance of eventual journal submission.

Yet another practical step of particular importance to IHRM researchers for whom English is not their first language is to seek professional copy-editing help. Also, there are several selfhelp books and online programs that can provide suggestions for appropriate use of grammar. Manuscripts with many spelling and grammatical errors are more likely to be rejected than manuscripts that are honed and polished. Poor writing leads to a frustrated reviewer who gets distracted by the errors and fails to focus on the main purpose of the manuscript. The quality of writing especially suffers when authors try to complete a manuscript in a short amount of time. It is important to note that manuscripts take time to 'mature' and shortcuts are a sure path to poor writing. 


\section{Responding to Reviewers}

Less than $10 \%$ of submissions to top-tier journals are invited to revise and resubmit (R\&R). Lower level journals are less likely to reject and more likely to offer an R\&R. Getting the manuscript accepted after that depends on how authors respond to the comments and suggestions from the Action Editor (AE) and the reviewers. One important thing to keep in mind is that journals exist for publishing manuscripts, rather than rejecting them. Getting an $R \& R$ for a submission may include some tough criticism but it is a success - one cannot do better than that. If a manuscript gets an $\mathrm{R} \& \mathrm{R}$, it implies that the $\mathrm{AE}$ sees value in it and is willing to work with the author to get it published. It may appear that reviewers are looking for all the potential reasons not to publish a manuscript, but the opportunity to revise and resubmit means that the $\mathrm{AE}$ is looking for reasons to publish it. Reviewers expend a lot of (anonymous, uncredited) time and effort in providing thoughtful feedback and writers should be appreciative of this. As far as possible, take a more detached or neutral perspective on the criticism and concerns the reviewers raise about the manuscript, read the comments more carefully, and digest them in more depth. This will help push thinking about the ideas to a new level and make the manuscript's contribution more significant. One approach some of us take is to read through the comments and then wait and allow the negative emotions (should they exist) to pass. Later, with a more objective frame and cooled emotions, author(s) can reassess the comments and more clearly see the potential developmental nature of their content.

The manuscript revision process and the work involved in responding to reviewers' comments can be stressful and even daunting. But making a good faith effort by being responsive to each and every point (no matter how trivial in the author's eyes) and highlighting the responses point-by-point in the editorial letter are extremely important. It is important to pay 
special attention to the AE's letter for several reasons. The $\mathrm{AE}$ is the person who makes the judgment in terms of the value of the manuscript to the existing literature. Carefully read the reviewer comments that the $\mathrm{AE}$ appears to be aligning with, and focus on addressing these first and foremost. This does not mean ignoring other comments, but these are the most critical issues on which the $\mathrm{AE}$ is likely to make a decision. The $\mathrm{AE}$ is the final gatekeeper of the manuscript's publication, regardless of what the reviewers say, the AE could make his/ her independent judgment defying their recommendations (it rarely happens, but it could happen). Of course it does not mean that authors need to agree with every point made by the AE; authors can choose to challenge a point, but they must provide convincing logic and reasoning, supported by both theory and empirics. It is important to keep/ maintain the strong aspects of the manuscript as much as possible, meanwhile strengthen the weak parts. Sometimes it is easy to be carried away by all of the changes and forget that it was the strength of the original core ideas that likely led the reviewers and the $\mathrm{AE}$ to recommend revision in the first place.

In responding to the AE's letter, starting with a summary of the major changes made to address the concerns is helpful because it provides the big picture about the scope of the revision. Specific notes should be made to indicate any newly improved theoretical framework or empirical findings included in the revision. After that, authors should respond to each of the comments in the letter by providing as much information as required to answer every question, with sincerity, care, and respect; as well as well-articulated reasoning and evidence.

The major concerns raised in the AE letter as well as in the reviewers' comments often include: (a) the significance of the theoretical contribution, (b) the rigor of the research design, data collection and data analyses, (c) the writing style and presentation, and (d) the practical implications of the findings in the context in which the study was conducted and beyond. 


\section{Addressing concerns of theoretical contribution}

Theoretical contributions in the manuscript may fall into any of the categories discussed earlier in this editorial. Many of the AE and the reviewers' concerns may echo around 'no new insights are offered by the findings'. This concern may be addressed by first taking a deep look at the manuscript to identify if this concern is a consequence of the authors' inability to highlight or communicate clearly the contribution to the reader, or is it possible that the reviewers are correct and there is marginal (if any) contribution. The researchers can also attempt to approach the research question from different theoretical angles and see where the contributions lie. If for example, the study analyses successful repatriation, then does it advance theories that apply to corporations or HRM practices or to individual differences?

'Theories of context' or emic approach (described earlier) pose a greater challenge in convincing the $\mathrm{AE}$ and the reviewers that the manuscript constitutes new theory that can explain the phenomenon observed in the foreign culture, which cannot be explained by any existing theories. The challenges manifest on several fronts: (a) identifying a novel phenomenon that has not been addressed in the existing literature and empirically demonstrating it; (b) composing a theoretical account for the phenomenon that is grounded in the particular cultural context, and showing that this theoretical account is related to, but distinct from existing theories; and (c) articulating why the new theoretical account might have the ability to explain similar phenomenon in another cultural context that shares similar characteristics. It is evident that this approach involves theory building, rather than theory testing (Colquitt \& Zapata-Phelan, 2007). If any of the three components are not present, the manuscript may be rejected. In other words, adopting this approach involves much more work (both theoretical and empirical), and time and 
effort in getting the manuscript accepted; but its contribution is also more significant and profound.

\section{Addressing concerns of methodological rigor}

The choice of methodology and analyses has to match the theoretical questions that the researcher is trying to answer. So for example, as mentioned earlier, it is not possible to claim causal relationships if the data are cross-sectional. Compared to addressing the theoretical contribution concern for IHRM research, it is relatively easier to address issues related to methodological rigor as it is more universal than context specific. Methodological rigor can be demonstrated throughout the entire research process, from study design, data collection, data analyses, and results reporting; provided that sensible decisions have been made at each critical decision point in the research journey. The revision may call for new analyses, dropping or adding variables, or reporting results in a specific format. It may ask for justification of use of control variables. Or it may ask for detailed explanation of the logic behind using a specific analytical strategy. Frequently, authors do not present complete analyses and yet claim support for their hypotheses. A common mistake, for example, includes a test for moderating effects without a report on a test for slope differences or the shape of the slopes in support of the hypotheses.

Unsurprisingly, reviewers are not always convinced with the results and may ask for additional data collection. It is more of a norm today than before that multiple studies should be conducted to test the theoretical model. These studies ought to include different samples, different settings, use different manipulations for the same variable, or involve different methods (e.g., both experiment and survey). The ultimate purpose is to demonstrate that the theory has both internal and external validity through consistent findings across samples, settings, 
manipulations, and methods. Conducting both experimental and survey studies will help in not only establishing the causal effects between the variables of the study, but also in demonstrating the generalizability of the findings.

\section{Addressing concerns of implications of findings in other cultures}

This task is relatively easy if the manuscript adopted rigorous methodology in proposing and testing new theoretical models, and the findings are robust demonstrating both internal and external validity. In such a situation, the findings should have the same implications in other cultural contexts that share similar characteristics (used in theorizing) as in the culture where the new theory was developed. For example, the theory of paternalistic leadership (Farh \& Cheng, 2000; Chen, Eberly, Chiang, Farh, \& Cheng, 2014) was originally developed based on the Chinese cultural philosophies such as Confucianism that values 'relationalism' and 'hierarchy' (Hwang, 1991), and 'legalism' advocating that a ruler should govern his country by the rule of law, tactics, and power (Watson, 1964). The theory articulates three behaviors characterizing paternalistic leadership: benevolence, authoritarianism, and morality, and hypothesizes how these influence employee work attitudes and behaviors independently and jointly. Accumulated research found that this theory also applies to other cultural contexts such as Japan, India, Turkey, Mexico (Pelligrini \& Scandura, 2008; Raghuram, 2011) that have cultural characteristics of high collectivism (i.e., relationalism) and high power distance (i.e., hierarchy and authority) (Hofstede, 1991). The implications are therefore evident.

\section{Myths and Misperceptions}

At the Conference, a number of issues were raised that fell into the category of 'myths and misperceptions', though it has to be said that we understand why each one was raised. Before considering each in turn, it may be helpful to point out that most manuscripts, regardless of 
design or context, get rejected. The fact that most do may lead to myths and misperceptions about the causes of that rejection. We note here some examples and our reactions to them.

Top journals prefer U.S. based research. Although it is true that most research that gets published in the top journals is from the U.S.A. or western countries, this is because up until recently most researchers had been from that country and most submissions had come from there. This is where the notion of 'international' as meaning 'anything outside the USA' comes from. But this is changing quickly and very visibly. U.S.-based journals are rapidly diversifying their editorial boards to include authors from non-U.S. based institutions. Editors and reviewers are enthusiastic about work that is not based in the U.S.A. There are now large numbers of authors from many different nationalities being published and quick glance at almost any of the major journals will show increasing numbers of non-North American authors. And by no means, all of them have been trained in U.S. schools, either. Editors at editorial board meetings regularly highlight the desire to have more international scholars and international research represented in the published manuscripts.

Top journals prefer Anglo-Saxon authors. See the previous answer. It is also true that articles have to be submitted in good English, so that editors and reviewers can see the argument in the manuscript without having to puzzle through and decipher meanings. This obviously gives an advantage to native English speakers. But top journals know this. The Journal of International Business Studies, for example, which has published quite a lot of work on IHRM, states in its instructions to authors: "we welcome manuscripts from authors whose first language is not English. Manuscripts must be formatted according to [our] guidelines. Authors... are encouraged to seek professional editing assistance prior to submission". That is good advice for increasing the chances of a favorable review. 
Top journals prefer single country research. As noted earlier, theoretical contributions become increasingly difficult to claim as a researcher begins to include multiple countries in a sample. It is challenging for researchers to carry out an inductive study with theorizing 'of context' in one country, which allows in-depth study of a phenomenon or to develop new constructs ('builders'). Expanding this to two or more contexts may become an even more unmanageable task. So yes, although journals will encourage in-depth single country studies, there are also several well-researched comparative studies that have found room in top tier journals. High quality research that spans multiple countries is highly valued precisely because it requires a lot of effort to do well.

Top journals expect that writers will apply 'western' theoretical lenses. There is a fundamental truth behind this myth but this is evolving. The development of most management theories coincides with the economic growth and internationalization in the west during the 1950s to 1980s. The surge in theory development during this period can be attributed to the objective of understanding management dilemmas of that time (Barkema et al, 2015). Unfortunately, international researchers have relied on these theories or something similar, to explain dilemmas in different contexts and this is not always appropriate. This approach does not reflect the complex reality of IHRM. Fortunately, journal editors are aware of this complexity and are strongly encouraging newer constructs and theorizing emerging from non-western lenses (see Barkema et al., 2015). What is required are some clear and systematic theories and explanations for the findings (Wright, 2015).

Top journals do not accept qualitative research. In reality all top journals are looking for research that uses a rigorous methodology which is appropriate to addressing the questions that the researcher has set out to answer, whether qualitative or quantitative in nature. Unfortunately, 
rigorous qualitative research is not an easy or a quick process (Bansal \& Corley, 2012; Gephart, 2004), nor is there a clear-cut methodology that can be learned in a short time (see the methodology section of this editorial). Consequently, most of researchers choose to collect quantitative data and run the numbers, and this is reflected in the largely predominant publication of quantitative studies. Top journals will embrace a high quality inductive study as this is very likely a study that is likely to be expander or a builder of theory. The Academy of Management Journal's information for contributors states that "all empirical methods, including but not limited to: qualitative, quantitative, field, laboratory, meta-analytic, ad combination methods are welcome". Likewise, Gephart (2004) notes that multiple research publications with a qualitative design have won the coveted AMJ Best Article Award.

Overall, our view is that some of these myths may have some basis, but they should not deter authors who are not from the U.S.A. from submitting their work to good journals. NonU.S. authors have as good a chance, and in some ways a better chance, of success than anyone else because of their deep understanding of the context. Editors encourage international scholars engaged in international research to publish in their journals but the standards are high and the process rigorous (and challenging).

\section{Conclusion}

We have provided many do's and don'ts in this editorial for preparing IHRM articles. The objective here has been to make helpful suggestions as carrying out international research has a unique set of challenges. In writing this editorial, we acknowledge that these are our views. These may not be entirely representative of opinions of other IHRM researchers - who may have viewpoints that reflect their realities. Our objective here has been to provide some basic 
guidelines to IHRM researchers before they launch their projects and increase the chances of getting published by adding rigor in the process. 


\section{References}

Aycan, Z. (2005), 'The interplay between cultural and institutional/structural contingencies in human resource management practices', International Journal of Human Resource Management, 16 (7), 1083-1119.

Bae, J., Chen, S. J., \& Lawler, J. J. (1998). Variations in human resource management in Asian countries: MNC home-country and host-country effects. International Journal of Human Resource Management, 9(4), 653-670.

Barley, S.R. (2006), 'When I write my masterpiece: Thoughts on what makes a paper interesting', Academy of Management Journal, 49, 16-20.

Barley, S.R. (2016), ' $60^{\text {th }}$ Anniversary Essay: Ruminations on How We Became a Mystery House and How We Might Get Out', Administrative Science Quarterly, 61(1), 1-8.

Beer, M., Boselie, P., \& Brewster, C. (2015). Back to the future: Implications for the field of HRM of the multi-stakeholder perspective proposed 30 years ago. Human Resource Management, 54(3), 427-438

Björkman, I., \& Xiucheng, F. (2002). Human resource management and the performance of Western firms in China. International Journal of Human Resource Management, 13(6), 853-864.

Brewster, C., Mayrhofer, W., \& Smale, A. (2016). Crossing the streams: HRM in multinational enterprises and comparative HRM. Human Resource Management Review, doi:http://dx.doi.org.ezaccess.libraries.psu.edu/10.1016/j.hrmr.2016.04.002.

Byron, K., \& Thatcher, S. M. (2016). Editors' comments: “What I Know Now That I Wish I Knew Then" - Teaching theory and theory building. Academy of Management Review, 41(1), 1-8. 
Campbell, D. \& Stanley, J. (1963). Experimental and quasi-experimental designs for research. Chicago, IL: Rand-McNally.

Cascio, W.F. (2012). Methodological issues in international HR management research. International Journal of Human Resource Management, 23(12), 2532-2545.

Charmaz, K. (2014). Constructing grounded theory. $2^{\text {nd }}$ edition. Los Angeles: Sage Publications. Charmaz, K., \& Smith, J. A. (2003). Grounded theory. In J. A. Smith (eds.), Qualitative Psychology: A practical guide to research methods. $2^{\text {nd }}$ edition. Los Angeles: Sage Publications.

Chen, X. P., Eberly, M. B., Chiang, T. J., Farh, J. L., \& Cheng, B. S. (2014). Affective trust in Chinese leaders: Linking paternalistic leadership to employee performance. Journal of Management, 40, 796-819.

Chuang, A., Hsu. R,S., Wang, AC., Judge, TA. (2015). Does West “fit” with East? In search of a Chinese model of person-environment fit. Academy of Management Journal, 58(2), 480510.

Colquitt, J.A., \& Zapata-Phelan, C.P. (2007). Trends in theory building and theory testing: A five-decade study of the Academy of Management Journal. Academy of Management Journal, 50(6), 1281-1303.

Cook, T. D., \& Campbell, D. T. (1979). Quasi-experimentation: Design and analysis issues for field settings. Boston, MA: Houghton Mifflin.

Delbridge, R., Hauptmeier, M. \& Sengupta, S. (2011), 'Beyond the enterprise: Broadening the horizons of International HRM', Human Relations, 64(4), 483-505.

Edwards, T., \& Kuruvilla, S. (2005). International HRM: national business systems, organizational politics and the international division of labour in MNCs. The 
International Journal of Human Resource Management, 16(1), 1-21.

Farh, J. L., \& Cheng, B. S. (2000). A cultural analysis of paternalistic leadership in Chinese organizations. In J. T. Li., A. S. Tsui, \& E. Weldon (Eds.), Management and organizations in the Chinese context (pp. 85-127). London: Macmillan.

Ferner, A. (1997). Country of origin effects and HRM in multinational companies. Human resource management journal, 7(1), 19-37.

Geertz, C. (1973/2000), The Interpretation of Cultures, Basic Books, New York, NY

Gephart, R. P. (2004). Qualitative research and the Academy of Management Journal. Academy of Management Journal, 47(4), 454-462.

Gephart, R. P. (2004). Qualitative research and the Academy of Management Journal. Academy of Management Journal, 47(4), 454-462.

Glaser, B. G., \& Strauss, A. L. (2009). The discovery of grounded theory: Strategies for qualitative research. Transaction publishers.

Goergen, M., Brewster, C., Wood, G. T., \& Wilkinson, A. (2012). Varieties of capitalism and investments in human capital. Industrial Relations, 51(2): 501-552.

Hinkin, T. R. (1995). A review of scale development in the study of behavior in organizations. Journal of Management, 21, 967-988.

Hinkin, T. R., \& Tracy, J. B. (1999). An analysis of variance approach to content validation. Organizational Research Methods, 2 (2), 175-186.

Hofstede, G. (1991). Cultures and Organizations: Software of the Mind. Berkshire: McGrawHill.

Hofstede, G., \& McCrae, R. R. (2004). Personality and culture revisited: Linking traits and dimensions of culture. Cross-cultural research, 38(1), 52-88. 
Hsieh, H. F., \& Shannon, S. E. (2005). Three approaches to qualitative content analysis. Qualitative health research, 15(9), 1277-1288.

Huff, A. S. (1999), 'Writing for scholarly publication'. Thousand Oaks, California: Sage Publications.

Huo, Y. P., Huang, H. J., \& Napier, N. K. (2002). Divergence or convergence: a cross-national comparison of personnel selection practices. Human Resource Management, 41(1), 3144.

Hwang, K. K. 2000. Chinese relationalism: Theoretical construction and methodological considerations. Journal for the Theory of Social Behaviour, 30 (2), 155-178.

Johanson, L.M. (2007), 'Sitting in Your Reader's Chair: Attending to Your Academic Sensemakers', Journal of Management Inquiry, 16(3), 290-294.

Kaufman, B. E. (2015). Evolution of strategic HRM as seen through two founding books: A 30th anniversary perspective on development of the field. Human Research Management, 54(3), 389-407

Keller, J., \& Loewenstein, J. (2011). The cultural category of cooperation: A cultural consensus model analysis for China and the United States Organizational Science, 22 (2), 299-319

Klein, K. J., \& Kozlowski, S. W. (2000). From micro to meso: Critical steps in conceptualizing and conducting multilevel research. Organizational Research Methods, 3(3), 211-236.

Klein, K. J., Dansereau, F., \& Hall, R. J. (1994). Levels issues in theory development, data collection, and analysis. Academy of Management Review, 19(2), 195-229.

Kristof-Brown, A. L., Zimmerman, R. D., \& Johnson, E. C. (2005). Consequences of individuals' fit at work: A meta-analysis of person-job, person-organization, persongroup, and person-supervisor fit. Personnel Psychology, 58, 281-342. 
Langley, A. (1999). Strategies for theorizing from process data. Academy of Management.the Academy of Management Review, 24(4), 691-710. Li, J. (2006). The interactions between person-organization fit and leadership style in Asian firms: an empirical testing. International Journal of Human Resource Management, 17, 1689-1706.

Lazarova, M., Morley, M.J., and Tyson, S. (2008), 'International Comparative Studies in HRM and Performance - The Cranet Data,' International Journal of Human Resource Management, 19 (11), 1995-2003.

LeBreton, J. M., \& Senter, J. L. (2008). Answers to 20 questions about interrater reliability and interrater agreement. Organizational Research Methods, 11(4), 815-852.

Mayrhofer, W., Brewster, C., Morley, M. J., \& Ledolter, J. (2011). Hearing a different drummer? Convergence of human resource management in Europe - A longitudinal analysis. Human Resource Management Review, 21(1): 50-67.

Morris, M. W., Leung, K., Ames, D., \& Lickel, B. (1999). Views from inside and outside: Integrating emic and etic insights about culture and justice judgment. Academy of Management Review, 24 (4), 781-796.

Parry, E., Stavrou-Costea,E. \& Morley, M.J. (2011), ‘The Cranet International Research Network on Human Resource Management in retrospect and prospect', Human Resource Management Review, 21 (1), 1-4.

Pellegrini, E. K., \& Scandura, T. A. 2008. Paternalistic leadership: A review and agenda for future research. Journal of Management, 34: 566-593.

Phillips, J. M., \& Gully, S. M. (in press). Global recruiting. In H. Goldstein, E. Pulakos, J. Passmore, and C. Semedo (Eds.), The Wiley Blackwell Handbook of the Psychology of Recruitment, Selection, and Retention. Hoboken, NJ: Wiley. 
Podsakoff, P. M., MacKenzie, S. M., Lee, J., \& Podsakoff, N. P. (2003). Common method variance in behavioral research: A critical review of the literature and recommended remedies. Journal of Applied Psychology, 88, 879-903.

Raghuram, S. (2011). Organizational identification among young software professional in India. International Journal of Human Resource Management, 22, 3913-3928

Ragins, B. R. (2012). Editor's comments: Reflections on the craft of clear writing. Academy of Management Review, 37(4), 493-501.

Ryan, A. N. N., McFarland, L., Baron, H., \& Page, R. (1999). An international look at selection practices: Nation and culture as explanations for variability in practice. Personnel Psychology, 52(2), 359-392.

Schuler, R.S., \& Rogovsky, N (1998). Understanding compensation practice variations across firms: The impact of national culture. Journal of International Business Studies, 29(1), $159-177$.

Smith, P. B. (2004). Acquiescent response bias as an aspect of cultural communication style. Journal of Cross-Cultural Psychology, 35(1), 50-61.

Strauss, A., \& Corbin, J. (1998). Basics of qualitative research: Techniques and procedures for developing grounded theory. Sage Publications, Inc.

Tanova, C., \& Holtom, B. C. (2008). Using job embeddedness factors to explain voluntary turnover in four European countries. The International Journal of Human Resource Management, 19(9), 1553-1568.

Tung, R. L. (2016). New perspectives on human resource management in a global context. Journal of World Business, 51(1), 142-152.

Vaiman, V., \& Brewster, C. (2015). How far do cultural differences explain the differences 
between nations? Implications for HRM. The International Journal of Human Resource Management, 26(2), 151-164.

Van de Vijver, F.J.R., \& Leung, K. (1997). Methods and data analysis for cross-cultural research. Thousand Oaks: Sage.

Watson, B. (1964). Han Fei Tzu: Basic writings. New York, Columbia University Press.

Whetten, D. (1989). What constitutes a theoretical contribution? Academy of Management Review, 4, 490-495.

Whetten, D. (2009). An examination of the interface between context and theory applied to the study of Chinese organizations. Management Organization Review, 5(1), 29-55.

Whetten, D.A. (1989), 'What Constitutes a Theoretical Contribution?' Academy of Management Review, 14(4), 490-495.

Wright, P. M. (2015). Rethinking Contribution. Journal of Management, 41(3), 765-768.

Bansal, P., \& Corley, K. (2012). Publishing in AMJ—Part 7: What's different about qualitative research?. Academy of Management Journal, 55(3), 509-513.

Zhang, Y, Waldman, D.A., Han, Y.L., \& Li, X.B. 2015. Paradoxical leader behavior in people management: antecedents and consequences. Academy of Management Journal, 58(2), $538-566$. 
Figure 1: Published Articles related to IHRM (Source: Web of Science)

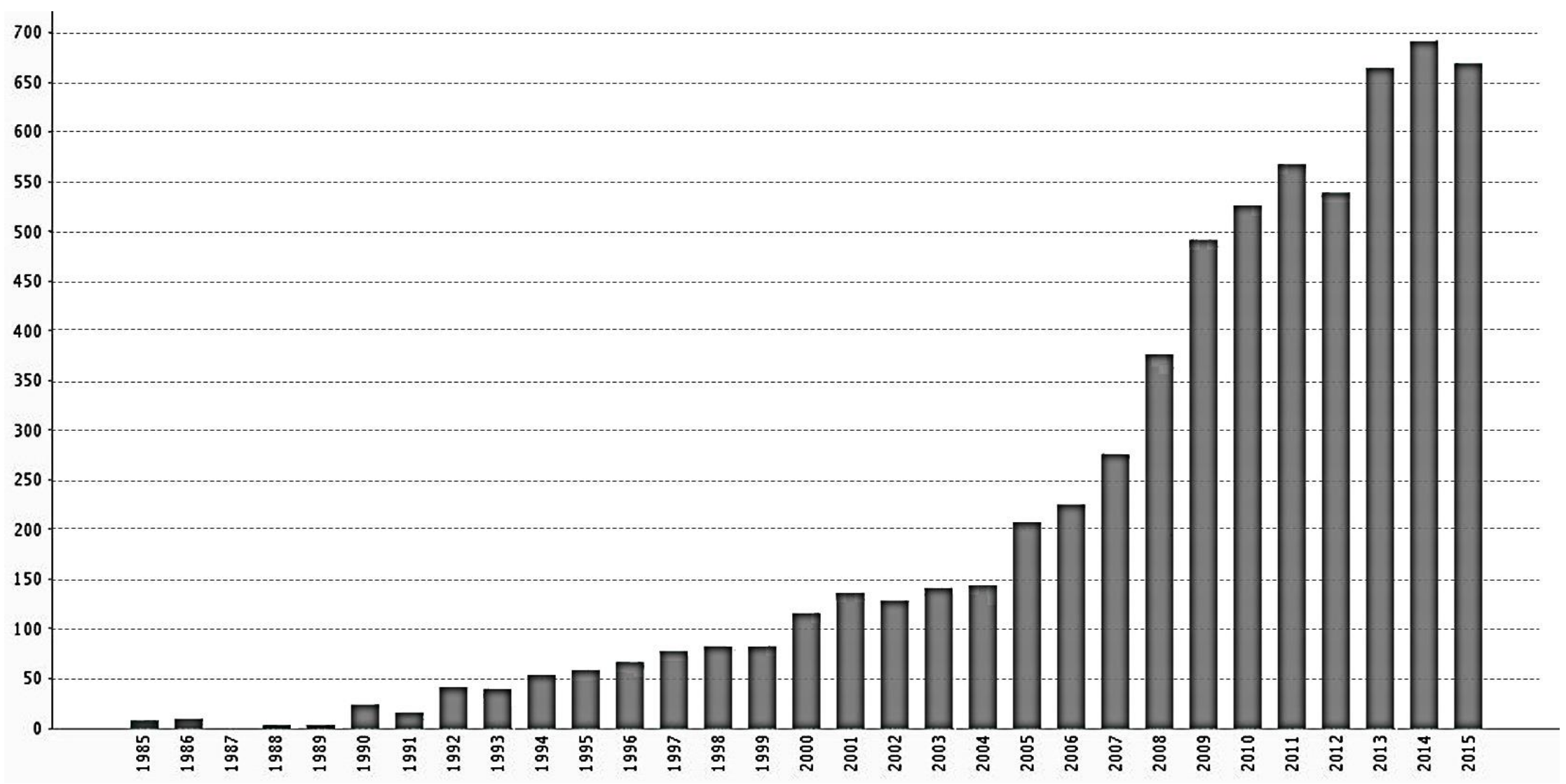


Figure 2: Citations of IHRM published articles (Source: Web of Science)

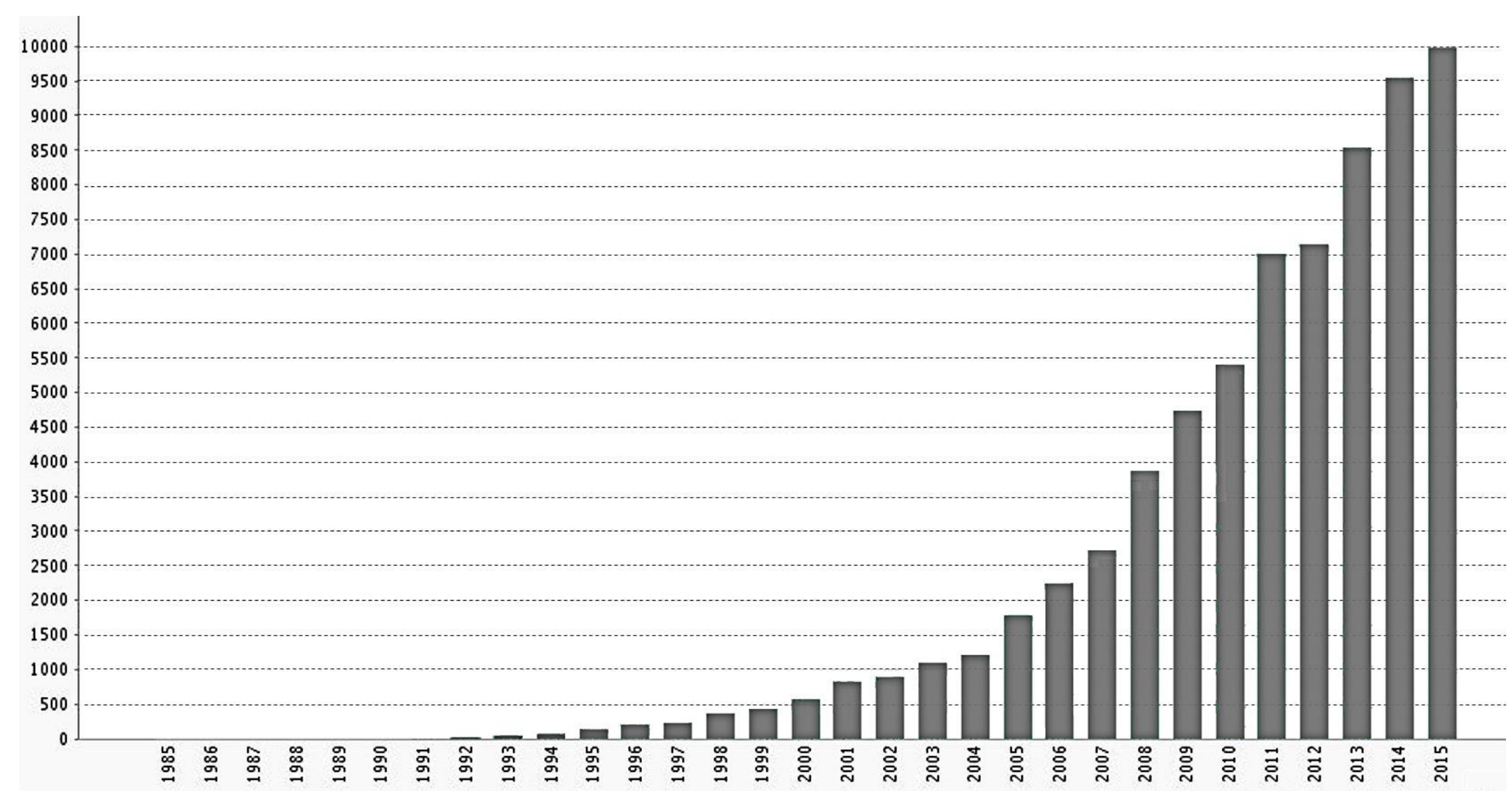

